\title{
Evaluation of knowledge and attitude of pharmacist and pharmacy technicians on emergency contraception method in Istanbul, Turkey: A simulated patient study
}

\author{
Gül Duygu UZUN 1 (D) , Mesut SANCAR 1 (D), Betül OKUYAN $1 *$ (D) \\ 1 Department of Clinical Pharmacy, Faculty of Pharmacy, Marmara University Haydarpaşa 34668 İstanbul, Turkey. \\ * Corresponding Author. E-mail: betulokuyan@yahoo.com (B.O.).
}

Received: 26 September 2018/ Revised: 11 November 2018 / Accepted: 13 November 2018

\begin{abstract}
Inappropriate use of drugs may contribute to therapeutic failure. Not only theoretical knowledge of pharmacists but also using this knowledge in counselling play a key role in improving compliance as far as avoiding failure. In terms of emergency contraception pill, this may lead to unwanted pregnancy. The aim of this study is to evaluate knowledge and attitude of pharmacists and pharmacy technicians on emergency contraception pills (ECP) on face to face talk by using simulated patient method. The study was conducted between March, 2015 and May, 2015 in community pharmacies located in Istanbul, Turkey. The simulated patient (SP), mystery shopper, filled in the standardized knowledge and evaluation form right after visiting each pharmacy. Main outcome measure is categorized as feature of pharmacy and consultant, questioning medical record of simulated patient, information of emergency contraception pill usage. In 115 community pharmacies included in the study, 37 (32.2\%) providers were pharmacist and $78(67.8 \%)$ were pharmacy technicians. There was no statistical difference between pharmacist and pharmacy technicians, neither pharmacists nor pharmacy technicians' performance were found high on questioning parameters, such as history of medication usage, chronic disease, history of contraception and menstruation status of SP ( $p>0.05)$, whereas the side effects of the ECP were explained more often by pharmacists in terms of profession comparison and by female consultants in terms of gender comparison $(\mathrm{p}<0.05)$. All these evidences underline the need to improve knowledge on emergency contraception method for both pharmacists and pharmacy technicians.
\end{abstract}

KEYWORDS: Emergency contraception; ulipristal acetate; pharmacist; pharmacy technician; simulated patient.

\section{INTRODUCTION}

Emergency contraceptive pills (ECP) are the method to avoid unwanted pregnancy after unprotected intercourse. There are also other method of emergency contraception (EC), such as intrauterine device option besides levonorgestrel, ulipristal acetate and combined oral contraceptive pills- Yuzpe method [1]. In Turkey, ulipristal acetate (UPA) was the only option while study was conducted however nowadays levonorgestrel is also an option beside UPA for EC [2].

Ulipristal acetate is the first selective progesterone receptor modulator approved for emergency contraception. Only one pill needs to be taken within 120 hours after unprotected intercourse. The success rate is maximum by using the pill within the first 24 hours, after that the success rate declines from 24 to 120 hours [3]. Ulipristal acetate's side effects are mostly mild and tolerable, such as headache, dysmenorrhea, nausea, weakness, and abdominal pain [4].

Despite the fact that non-prescribed medication concept is officially not defined in Turkey, ECP can be provided in community pharmacies without prescription [5]. In Turkey, all of the drugs should be dispensed by prescription according to the Pharmaceuticals and Medical Preparations Law [6]. Nevertheless Ministry of Health focus on growth hormone, antibiotics, antihistaminics and antidepressants in addition to controlled substance such as pregabalin, gabapentin, pseudoephedrine etc [7].

However Turkish Society of Obstetrics and Gynecology published guide for oral contraceptions in 2012 [8], UPA was not mentioned since drug have been licensed at the end of 2013. Since then there has not been any updated guideline about oral contraception or emergency contraception in Turkish.

How to cite this article: Uzun GD, Sancar M, Okuyan B. Evaluation of knowledge and attitude of pharmacist and pharmacy technicians on emergency contraception method in Istanbul, Turkey: A simulated patient study. J Res Pharm. 2019; 23(3): $395-402$. 
Essential information, which facilitates to achieve pharmaceutical goal, could be only attained in pharmacies owing to the fact that the patient, in need of ECP, directly visits the pharmacies.

In Turkey, simulation method in health science- medicine and nursing- is seen as to contribute to success in education by being used as a training practice [9]. Although according to some there is an ethical doubt for using this method in scientific researches, it has been highlighted that this method is extremely valuable and unique to evaluate knowledge and attitude in the practical field of pharmacy which might diverse from theories [10].

\subsection{Aim of the study}

The aim of this study based on simulated patient method is to gain the most actual feedback about practical reality and to find the most proper solutions for ECP consultation. This study seeks to evaluate knowledge and attitude of pharmacist and pharmacy technicians on emergency contraception practice by using simulated patient method.

\subsection{Ethics approval}

Ethics approval was obtained from the Marmara University Institute of Health Science Ethic Committee along with Istanbul Pharmacist Chamber.

\section{RESULTS}

Out of the 119 pharmacies 2 pharmacies did not have the ECP and just called for next patient right after stating out of stock while another two pharmacies handed out only the brochure of ECP's company which explains only when, how to take pill and some mild side effects. Thus, four of the pharmacies were excluded from the study due to the fact that the aim of the present study is to evaluate the counselling services provided by pharmacists and pharmacy technicians on emergency contraception pills (ECP).

\subsection{Features of pharmacies and staff}

Total of 115 pharmacies included in this study, the simulated patient was counselled by $37(32.2 \%)$ pharmacists and $78(67.8 \%)$ pharmacy technicians. Gender of professional consultants, were $49(42.6 \%)$ female and $66(57.4 \%)$ male. The feature of the pharmacies and personnel is shown below in Table 1.

Table 1. Feature of pharmacies and personnel.

\begin{tabular}{lcc}
\hline Title & $\mathbf{n}$ & \% \\
\hline Pharmacist & 37 & 32.2 \\
Pharmacy technician & 78 & 67.8 \\
Gender & & \\
Female & 49 & 42.6 \\
Male & 66 & 57.4 \\
Pharmacy occupancy rate during SP visit & & \\
Employee $>$ Patient & 80 & 69.57 \\
Employee $\leq$ Patient & 35 & 30.43 \\
\hline$\quad \mathrm{n}=$ number & &
\end{tabular}

\subsection{ECP counselling according to professional qualification}

None of the 115 pharmacies that took part in this study asked the SP about current medication usage, health problem or regular contraception method nor suggested a pregnancy test to the SP. Moreover, only one female pharmacist asked the SP about the time of her last menstruation and the time of the last unprotected intercourse. 
All of the 115 pharmacy consultants explained the administration way of ECP. Out of 37 pharmacists, 31 pharmacists $(83.8 \%)$ explained when the ECP should be taken while out of 78 technicians, $65(83.3 \%)$ pharmacy technicians explained the required timing for the use of the ECP. However, only $19(61.3 \%)$ out of 31 pharmacists provided correct information regarding the timing of the use of the ECP after unprotected intercourse. In terms of 65 technicians counselling the SP about the timing, 36 technicians $(55.4 \%)$ provided correct information. Even though all of the consultants, explained the timing, indicated after unprotected intercourse, only 120 hours response is accepted as correct information.

Out of 37 consulting pharmacists 17 pharmacists (45.9\%) and out of 77 technicians 15 technicians $(19.5 \%)$ provided correct information about the side effects of the ECP $(p<0.05)$. Stated at least one side effect is accepted as correct information. All the above is presented in Table 2.

Table 2. Attitude on ECP counselling according to the profession.

\begin{tabular}{|c|c|c|}
\hline & $\begin{array}{c}\text { Pharmacist } n=37 \\
n / N^{1}(\%)\end{array}$ & $\begin{array}{c}\text { Pharmacy } \\
\text { Technicians n=78 } \\
\text { n/ N2(\%) }\end{array}$ \\
\hline $\begin{array}{l}\text { Information provided about how to use } \\
\text { the ECP }\end{array}$ & $\begin{array}{l}37 / 37 \\
(100 \%)\end{array}$ & $\begin{array}{l}78 / 78 \\
(100 \%)\end{array}$ \\
\hline $\begin{array}{l}\text { Information provided about when to use } \\
\text { the ECP }\end{array}$ & $\begin{array}{l}31 / 37 \\
(83.8 \%)\end{array}$ & $\begin{array}{c}65 / 78 \\
(83.3 \%)\end{array}$ \\
\hline $\begin{array}{l}\text { Correct information provided about } \\
\text { when to use the ECP }\end{array}$ & $\begin{array}{l}19 / 31 \\
(61.3 \%)\end{array}$ & $\begin{array}{l}36 / 65 \\
(55.4 \%)\end{array}$ \\
\hline $\begin{array}{l}\text { Correct information provided about the } \\
\text { side effects of the ECP* }\end{array}$ & $\begin{array}{c}17 / 37 \\
(45.9 \%)\end{array}$ & $\begin{array}{c}15 / 77 \\
(19.5 \%)\end{array}$ \\
\hline $\begin{array}{l}\text { Information provided about how to avoid } \\
\text { possible nausea and vomiting }\end{array}$ & $1 / 37$ & $0 / 78$ \\
\hline $\begin{array}{l}\text { Information provided about what to do in } \\
\text { case of unexpected circumstances }\end{array}$ & $0 / 37$ & $0 / 78$ \\
\hline $\begin{array}{l}\text { Information provided about what to do if } \\
\text { vomiting occurs within the first hour } \\
\text { after taking the ECP }\end{array}$ & $\begin{array}{l}2 / 37 \\
(5.4 \%)\end{array}$ & $\begin{array}{c}4 / 78 \\
(5.1 \%)\end{array}$ \\
\hline
\end{tabular}

\subsection{Attitude of ECP consultants according to occupancy rate of pharmacy}

Moreover, in terms of providing information about the time for when to use the ECP, there is a statistically significant difference in relation to pharmacy occupancy rate. Out of 96 pharmacies that provided correct/incorrect information about the time for when to use the ECP, 70 pharmacies had more employees than patients at the visiting time of the SP while in 26 pharmacies the number of the employees was less or equal than the number of patients. Out of the above mentioned 70 pharmacies, 46 pharmacies $(65.7 \%)$ provided correct information about the time for when to use the ECP. Out of the above mentioned 26 pharmacies, 9 pharmacies $(34.6 \%)$ provided correct information regarding the timing while 17 pharmacies $(65.4 \%)$ provided incorrect information $(\mathrm{p}<0.05)$. Table 3 below illustrates the attitude on ECP consultation according to pharmacy occupancy rate. 
Tablo 3. Attitude of ECP consultants according to pharmacy occupancy rate.

\begin{tabular}{|c|c|c|}
\hline & $\begin{array}{l}\text { Employee } \\
\text { >Patient } \\
\text { n/N1(\%) }\end{array}$ & $\begin{array}{l}\text { Employee } \\
<\text { Patient } \\
\text { n/N2(\%) }\end{array}$ \\
\hline $\begin{array}{l}\text { Information provided about how to use the } \\
\text { ECP }\end{array}$ & $85 / 85$ & $30 / 30$ \\
\hline $\begin{array}{l}\text { Information provided about when to use the } \\
\text { ECP }\end{array}$ & $\begin{array}{c}70 / 85 \\
(82.4 \%)\end{array}$ & $\begin{array}{c}26 / 30 \\
(86.7 \%)\end{array}$ \\
\hline $\begin{array}{l}\text { Correct information provided about when to } \\
\text { use the } \mathrm{ECP}^{*}\end{array}$ & $\begin{array}{l}46 / 70^{*} \\
(65.7 \%)\end{array}$ & $\begin{array}{l}9 / 26^{*} \\
(34.6 \%)\end{array}$ \\
\hline $\begin{array}{l}\text { Correct information provided about the side } \\
\text { effects of the ECP }\end{array}$ & $\begin{array}{c}25 / 84 \\
(29.8 \%)\end{array}$ & $\begin{array}{c}7 / 30 \\
(23.3 \%)\end{array}$ \\
\hline $\begin{array}{l}\text { Information provided about how to avoid } \\
\text { possible nausea and vomiting }\end{array}$ & $1 / 84$ & $0 / 30$ \\
\hline $\begin{array}{l}\text { Information provided about what to do in } \\
\text { case of unexpected circumstances }\end{array}$ & $0 / 85$ & $0 / 30$ \\
\hline $\begin{array}{l}\text { Information provided about what to do if } \\
\text { vomiting occurs within the first hour after } \\
\text { taking the ECP }\end{array}$ & $\begin{array}{l}5 / 85 \\
(5.9 \%)\end{array}$ & $\begin{array}{l}1 / 30 \\
(3.3 \%)\end{array}$ \\
\hline
\end{tabular}

\subsection{Attitude of ECP consultants according to gender}

Furthermore, in terms of providing information about the side effects of the ECP, there is another statistically significant difference in relation to gender of ECP consultant. Out of 49 ECP female consultants, $20(40.8 \%)$ provided correct information about the side effects of the ECP whereas out of 65 ECP male consultants, $12(18.5 \%)$ provided correct information. Table 4 below illustrates the attitude of ECP consultants according to gender.

Table 4. Attitude of ECP consultants according to gender.

\begin{tabular}{lcc}
\hline Consultant & $\begin{array}{c}\text { Female } \\
\text { n/N1(\%) }\end{array}$ & $\begin{array}{c}\text { Male } \\
\text { n/N2(\%) }\end{array}$ \\
\hline Information provided about how to use the ECP & $49 / 49$ & $66 / 66$ \\
& $41 / 49$ & $55 / 66$ \\
& $(83.7 \%)$ & $(83.3 \%)$ \\
Information provided about when to use the ECP & $27 / 41^{*}$ & $28 / 55^{*}$ \\
& $(65.9 \%)$ & $(50.9 \%)$ \\
$\begin{array}{l}\text { Correct information provided about when to use the } \\
\text { ECP }\end{array}$ & $20 / 49^{*}$ & $12 / 66^{*}$ \\
$\begin{array}{l}\text { Correct information provided about the side effects of } \\
\text { the ECP* }\end{array}$ & $(40.8 \%)$ & $(18.5 \%)$ \\
$\begin{array}{l}\text { Information provided about how to avoid possible } \\
\text { nausea and vomiting }\end{array}$ & $1 / 49$ & $0 / 66$ \\
$\begin{array}{l}\text { Information provided about what to do in case of } \\
\text { unexpected circumstances }\end{array}$ & $0 / 66$ & $0 / 66$ \\
$\begin{array}{l}\text { Information provided about what to do if vomiting } \\
\text { occurs within the first hour after taking the ECP }\end{array}$ & $2 / 49$ & $4 / 66$ \\
\hline
\end{tabular}

\section{DISCUSSION}

This study reflects on the attitude and knowledge of the pharmacists and pharmacy technicians in regard of providing information about the ECP to the patients. The study is conducted by simulated patient method, that is not to judge the pharmacists or pharmacy technicians but to gain the most actual feedback about practical reality, and results in illustrating that the pharmacists and pharmacy technicians of 115 randomly chosen community pharmacies that took part of this study either did not have appropriate knowledge about the ECP (since incorrect information was provided) or could not provide a suitable and satisfactory counselling about ECP. 
Similarly, a study conducted in Australia in 2011 demonstrates that the rate regarding the essential information provided in terms of the time for when to use the ECP is likewise high [11].

Although the rate regarding the essential information provided in terms of the time for when to use the ECP is high in this study, it is questionable whether this information is correct or not. As seen in this study, among those pharmacies that were busier at the time of the visiting SP, seen from the rate of the employees and patients, the correct information was provided only by $34 \%$ while among those pharmacies that were less busy $65 \%$ were able to provide correct information to the SP.

However, it is important to keep in mind what is considered as providing an incorrect information by the consultant to the SP and the reason for it in this study. Unlike the study conducted in 2011 in Nicaragua by Ehrle and Sarker, which lists incorrect information as wrong information given on the bases of time to take the ECP, such as taking the pill before the intercourse, which was given by almost $10 \%$ of the consultants, this study did not record such misleading information that would lead to a total therapeutic failure [12]. What this study considers as incorrect information is in regard of the time period of the effect of the ECP that the consultant failed to provide correctly- instead of 120 hours within which the pill might be taken, the consultant informed the SP that the pill ought to be taken only within 72 hours, that is a characteristic for levonorgestrel, without even asking about the time of the last unprotected intercourse. In this case, the patient in need of the ECP could have given up purchasing the pill if the last unprotected intercourse had occurred in between 72 and 120 hours, in which the pill would still be effective. This could have led to unwanted consequences due to incorrect information provided by the consultant.

This study has some notable strengths such as random sampling and inclusion of occupancy rate measure. On the other hand, there are also weaknesses for this study: despite the fact that ECP package insert provides information for users as far as risks and contraindications are accepted as low, comprehensive usage or knowledge of ECP in Turkey is still not quite substantial [13]. Even though age of data is 2015, we are in believe that would not change the results of this study.

Another study conducted in 2012 in Turkey by Apikoğlu, Clark and Izzettin demonstrate that $16 \%$ of the consultants feel more confident counselling a patient of the same gender [14]. The study conducted in 2013 in Delhi shows similar results according to the survey [15]. It is worth mentioning that according to academic literature, there is a significant difference between studies based on survey and studies based on simulated patient method in regard of the evaluation of counselling of either pharmacists or pharmacy technicians [1115]. The current study regarding ECP, based on simulated patient method, also shows a significant difference when compared to similar studies based on survey method. This situation manifests that the reality of the practice of the consultants is different from the information provided by them in a survey, hence the method of simulated patient ought to be preferred for likewise studies. Yet, since the current study does not employ a survey method, which could have been conducted among the identical participants and could have shown the difference between the two methods more clearly, it might be argued that this is one of the limiting factors of this study.

Unlike the study conducted in 2002 in Sweden by Aneblom, Lundborg, Carlsten, Eurenius and Tydén, demonstrating that $80 \%$ of pharmacy consultants asked about the time of the last intercourse, in this present study conducted in Turkey, it has been shown that only one female pharmacist asked the SP about her last unprotected intercourse [16]. It may be the result of patriarchal structure in Turkey, that cooperation of health providers and sociologists for further studies could be beneficial.

Another important point is that a statistically significant difference occurs regarding the information provided about the side effects of the ECP when considered the title (pharmacist vs. pharmacy technician) and the gender of the consultant $(\mathrm{p}<0.05)$. Unlike the study conducted in Turkey in 2011 by Apikoğlu, Sancar, Okuyan and Izzettin, demonstrating that according to a survey the rate of the pharmacy technicians providing information about the side effects of the ECP was high, this study shows that only $19.5 \%$ of technicians provided such information to the SP, while $80.5 \%$ of technicians clearly denied any side effects of the ECP [5]. In the present study, 17 pharmacists (45.9\%) out of 37 provided correct information about the side effect while 20 pharmacists $(54.1 \%)$ denied any side effects of the ECP $(p<0.05)$. As seen, the difference between the title (pharmacist vs. pharmacy technician) has underlined the significance of the consultant, showing that the patient ought to be counselled by a pharmacist not a technician. The same difference occurs in regard of the gender of the consultant, demonstrating that female consultants were more efficient to provide the SP with the information about the side effects of the ECP. This might be due to the possible personal use of the ECP by the consultant, however, this data also strongly suggests a further research on this topic within the field of social pharmacy. 


\section{CONCLUSION}

The data of this study clearly indicates that both the pharmacists and the pharmacy technicians ought to update their knowledge regarding ECP to provide a sufficient counselling to their patients. Moreover, this study also demonstrates a fundamental lack of taking patient's history, which is one of the essential steps of pharmaceutical care. Thus, what this study suggests is that in order to provide a standardized counselling in pharmacies, various steps are required, such as professional development workshops for the pharmacy personnel, written guides for health care providers, brochures/ leaflets for patients, etc. This is important, especially since as to ECP in Turkey, the pharmacies are the direct source for patients, because there is no need of counselling a doctor or another health care provider to get access to ECP.

Further studies should be conducted to improve knowledge and attitude of both pharmacists and pharmacy technicians on emergency contraception method such as quasi-experimental study design including evaluation of pre- and post-education program.

\section{MATERIALS AND METHODS}

The study is conducted between March the $4^{\text {th }}$ and May the $7^{\text {th }}, 2015$ in Istanbul among community pharmacies by using simulated patient (SP) method. The SP of this study, who is over 18 and female, has been informed about the case and the importance of confidentiality by the researchers of this study.

The sample size of this study, with $95 \%$ confidence level and 10\% margin of error, is calculated as at least 94 from the total of 5124 pharmacies in Istanbul. The pharmacies were listed by using shift list of Istanbul Pharmacist Chamber from which 119 pharmacies were chosen. The selection of pharmacies, which were visited by SP, were determined by using random numbers.

The SP enters the pharmacy, waits until one of the pharmacy employee approaches then, the SP asks for ECP and acts according to the simulated patient data shown in Table 5 which is inspired by the research of Queddeng K, Chaar B and Williams K [11].

Table 5. Simulated patient data.

\begin{tabular}{ll}
\hline Patient & Female \\
\hline Request reason & Unprotected intercourse \\
Drug use & None \\
Health problem & None \\
Regular Contraception & Withdrawal method \\
Method & (interrupted intercourse) \\
Last Period & 15 days ago \\
Others & Never used ECP \\
& Regular menstruation \\
& Pregnancy test not applied \\
\hline
\end{tabular}

The SP leaves the pharmacy without buying ECP or anything else suggested by pharmacists or pharmacy technicians. The consultation between the SP and the pharmacist or the pharmacy technician has not been recorded due to ethical issues.

Immediately after visiting the pharmacy, the SP fills in the knowledge and evaluation form shown in Table 6, contributing to gathering data for this study, which among others reflect on the ECP counselling service given in pharmacies and the patient medical history acquired by the pharmacist or pharmacy technician. Checklist, shown in Table 2, is consist of three sections as features of pharmacy and consultant, medical record of SP and information of ECP usage.

\subsection{Features of pharmacy and consultant}

The title and the gender of the person counselling the SP is recorded. Although the presence of the pharmacist in the pharmacy is mandatory in Turkey, the technicians might consult the patients regarding their medications [18]. Whether the SP was counselled by a pharmacist, has been determined by SP according to the obligatory practice in Turkey as the pharmacist's photograph ought to be displayed in a pharmacy. Apart from the person on photograph identified as the pharmacist or any other employee with a name badge displaying a pharmacist title, every other person is considered as a pharmacy technician. In addition, since 
one of the data of this study is concerned with the occupancy rate of the pharmacies, it has been calculated according to the number of employees and patients during the $\mathrm{SP}^{\prime} \mathrm{s}$ visit.

Table 6. Checklist used by simulated patient.

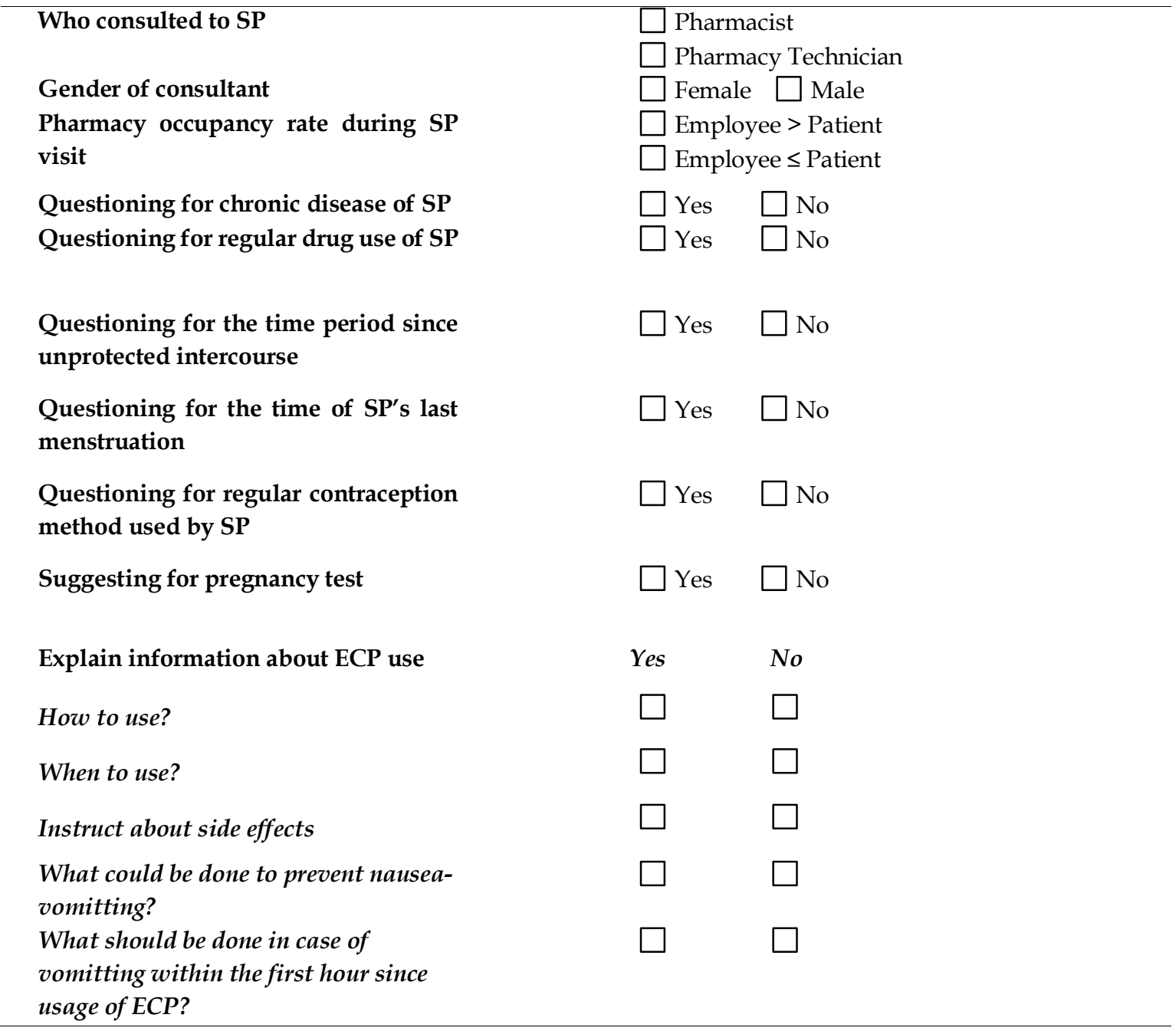

\subsection{Questioning medical record of simulated patient}

In this part, SP recorded not only if consultant questioned for chronic disease, regular drug use, time period since unprotected intercourse, time of $\mathrm{SP}^{\prime} \mathrm{s}$ last menstruation and regular contraception method but also if they suggest for pregnancy test. Answers were recorded as yes if they mentioned and no if they don't mention.

\subsection{Information of ECP usage}

SP recorded if consultant mentioned that; how to use ECP, when to use ECP, what are common side effects, what could be done to prevent nausea or vomiting and what should be done in case of vomiting within first hours since usage of ECP. In addition SP also recorded exact time limit, those consultants expressed for using ECP, to evaluate right answer, 'till 120 hours', percentage.

\subsection{Statistical analysis}

All variables are presented as mean \pm standard deviation for continuous variables while nominal and ordinal data are presented as number (n) and percentage. Categorical variables were analyzed by Chi-Square test by using SPSS 11 (Statistical Package for Social Sciences) and $p<0.05$ was evaluated as a statistically significant. 
Author contributions: Concept - B.O., G.D.U, M.S.; Design - B.O., G.D.U, M.S.; Supervision - B.O., M.S; Materials B.O., G.D.U, M.S; Data Collection and/or Processing - G.D.U.; Analysis and/or Interpretation - B.O., G.D.U, M.S.; Literature Search - B.O., G.D.U, M.S.; Writing - B.O., G.D.U.; Critical Reviews - B.O., G.D.U, M.S.

Conflict of interest statement: The authors declared no conflict of interest.

\section{REFERENCES}

[1] Batur P, Cleland K, McNamara M, Wu J, Pickle S; EC Survey Group. Emergency contraception: A multispecialty survey of clinician knowledge and practices. Contraception. 2016;93(2):145-152. [CrossRef]

[2] Turkish Medicines and Medical Devices Agency. Ruhsatlı Ürünler Listesi (Licensed Products List). https://www.titck.gov.tr/dinamikmodul/85 (accessed on November 11, 2018).

[3] Gemzell-Danielsson K, Trussell J. What do we need to know about emergency contraception. Contraception. 2013; 88(5): 585-586. [CrossRef]

[4] Glasier AF, Cameron ST, Fine PM, Logan SJ, Casale W, Van Horn J, Sogor L, Blithe DL, Scherrer B, Mathe H, Jaspart A, Ulmann A, Gainer E. Ulipristal acetate versus levonorgestrel for emergency contraception: A randomised non-inferiority trial and meta-analysis. Lancet. 2010; 375(9714):555-562. [CrossRef]

[5] Apikoglu-Rabus S, Sancar M, Okuyan B, Izzettin FV. Turkish pharmacy technicians' counseling practices and attitudes regarding emergency contraceptive pills. Afr J Pharm Pharmacol. 2011; 5(1):60-66. [CrossRef]

[6] Ministry of Health of Turkey. 1262 numaralı İspençiyari ve Tibbi Müstahzarlar Kanunu (1262 numbered Law on Pharmaceuticals and Medical Preparations,1928). http://www.mevzuat.gov.tr/MevzuatMetin/1.3.1262.pdf (accessed on November 11, 2018).

[7] Turkish Medicines and Medical Devices Agency Public Statement. https://www.titck.gov.tr/haber/recetesiz-ilac-satisigenelgesi-hakkinda-15-05-13-27122018173942 (accessed on November 11, 2018).

[8] Oral Kontrasepsiyon Kılavuzu (Guideline for Oral Contraception, 2012). http://www.tjod.org/tjod-oral-kontrasepsiyonklavuzu/ (accessed on November 11, 2018).

[9] Karadag M, Calıskan N, Iseri O. Effects of case studies and simulated patients on students' nursing care plan. Int J Nurs Knowl. 2016;27(2):87-94. [CrossRef]

[10] Weiss MC, Booth A, Jones B, Ramjeet S, Wong E. Use of simulated patients to assess the clinical and communication skills of community pharmacists. Pharm World Sci. 2010;32(3):353-361. [CrossRef]

[11] Queddeng K, Chaar B, Williams K. Emergency contraception in Australian community pharmacies: A simulated patient study. Contraception. 2011;83(2):176-182. [CrossRef]

[12] Ehrle N, Sarker M. Emergency contraceptive pills: knowledge and attitudes of pharmacy personnel in Managua, Nicaragua. Int Perspect Sex Reprod Health. 2011;37(2):67-74. [CrossRef]

[13] Atan ŞÜ, Kavlak O, Kulak E, Bozkaya M. Attitudes towards family planning among women seeking induced abortion in Izmir, Turkey. Eur J Contracept Reprod Health Care. 2011; 16(3):194-200. [CrossRef]

[14] Apikoglu-Rabus S, Clark PM, Izzettin FV. Turkish pharmacists' counseling practices and attitudes regarding emergency contraceptive pills. Int J Clin Pharm. 2012;34(4):579-586. [CrossRef]

[15] Mishra A, Saxena P. Over-the-counter sale of emergency contraception: A survey of pharmacists in Delhi. Sex Med. 2013; 1(1):16-20. [CrossRef]

[16] Aneblom G, Lundborg CS, Carlsten A, Eurenius K, Tydén T. Emergency contraceptive pills over-the-counter: practices and attitudes of pharmacy and nurse-midwife providers. Patient Educ Couns. 2004; 55(1):129-135. [CrossRef]

[17] Tavares MP, Foster AM. Emergency contraception in a public health emergency: exploring pharmacy availability in Brazil. Contraception. 2016; 94(2):109-114. [CrossRef]

[18] Sancar M, Tezcan E, Okuyan B, Izzettin F.V. Assessment of the attitude of community pharmacists and pharmacy technicians towards diarrhea: A simulated patient study in Turkey. Trop J Pharm Res. 2015; 14(8):1509-1515. [CrossRef] 